\title{
Identifying medication errors in the neonatal intensive care unit and paediatric wards using a medication error checklist at a tertiary academic hospital in Gauteng, South Africa
}

A Truter, BPharm, MPharm; N Schellack, BCur, BPharm, PhD (Pharmacy); J C Meyer, BPharm, MSc (Med), PhD (Pharmacy)

Department of Pharmacy, Faculty of Health Sciences, School of Health Care Sciences, Sefako Makgatho Health Sciences University, Pretoria, South Africa

Corresponding author: A Truter (archele.truter@live.com)

\begin{abstract}
Background. Paediatric patients are particularly prone to medication errors as they are classified as the most fragile population in a hospital setting. Paediatric medication errors in the South African healthcare setting are comparatively understudied.

Objectives. To determine the incidence of medication errors in neonatal and paediatric inpatients, investigate the origin of medication errors that occurred and describe and categorise the types of medication errors made in both the neonatal intensive care unit (NICU) and paediatric wards.

Methods. The study followed a prospective, quantitative design with a descriptive approach. A prospective record review of inpatients' medication charts was undertaken to determine what was prescribed by the physician, dispensed by the pharmacy and administered by the nurses. The researcher also directly observed the preparation and administration techniques as performed by the nurses. A medication error checklist was used to collect the data.

Results. A total of 663 medication errors were detected in 227 patients over the study period of 16 weeks, of which 177 (78\%) patients had one or more error(s). There were 338 (51\%) administration errors and $309(47 \%)$ prescribing errors. Incorrect dosing was the most frequent type of error (34\%), followed by omission of medication (18.5\%) and medication given at the incorrect time (12\%). The causes of these medication errors were mostly due to miscalculation (26\%), failure to monitor (15\%) and procedures not followed (15\%). Anti-infectives (43\%) and analgesics (25\%) had the most errors. In 118 (67\%) patients the errors resulted in no harm to the patient, whereas in 59 (33\%) patients the medication error resulted in some level of harm.

Conclusion. The incidence of medication errors in the NICU and paediatric wards at the teaching hospital was higher than values reported elsewhere globally. Most errors occur during prescribing and administration of medication. Dosing errors are a common problem in paediatrics. Therefore, a formalised system to record these errors should be introduced alongside regular discussions on preventive measures among the multidisciplinary team.
\end{abstract}

S Afr J Child Health 2017;11(1):5-10. DOI:10.7196/SAJCH.2017.v11i1.1101

Medication errors in paediatrics are relatively understudied in South Africa (SA). The National Coordinating Council for Medication Error Reporting and Prevention (NCC MERP) defines a medication error as 'any preventable event that may cause or lead to inappropriate medication use or patient harm while the medication is in the control of the health care professional, patient, or consumer. Such events may be related to professional practice, healthcare products, procedures, and systems, including prescribing, order communication, product labelling, packaging, and nomenclature, compounding, dispensing, distribution, administration, education, monitoring, and use. ${ }^{[1]}$

Most medications used in paediatrics are used off-label and hence adult dosage forms are administered, which may increase opportunities for medication errors with subsequent risks for the patient. ${ }^{[2]}$ The most error-prone step in the medication process is prescribing by the prescriber. ${ }^{[3]}$ Dosing errors are the leading cause of medication errors, especially in the paediatric population and more so in the intensive care unit (ICU) ${ }^{[3]}$ Paediatric patients require individualised prescribing of medication based on their age and body weight, together with the interpretation of the therapy outcome. ${ }^{[4]}$

There are five stages of the medication process where medication errors can occur, called the origin of medication errors, ${ }^{[5,6]}$ i.e.: prescribing of medication by a legitimate prescriber; transcribing of the order documentation by someone other than the prescriber for ordering and processing; dispensing, whereby a pharmacist assesses a medication order and releases the product for use by another healthcare professional; administration, where the medication is administered to the patient, including administration of the correct medication to the correct patient at the prescribed time and labelling the current intravenous medication that the patient is receiving; and monitoring to evaluate the patient's response to medication and record the findings. ${ }^{[5,6]}$

The following types of medication errors are identified and described by various studies: incorrect medicine, incorrect dose, incorrect preparation, expired product, incorrect time, incorrect route, unauthorised medication, omission, wrong patient, mislabelling, incorrect dispensing, incorrect duration of treatment, extra dose, deteriorated medication and contraindication. ${ }^{[5,7-10]}$

The classes of drugs mostly involved in paediatric medication errors include anti-infectives, sedatives, analgesics, bronchodilators and cardiovascular drugs. ${ }^{[11-13]}$

The causes of medication errors in general clinical practice can be divided into human and system errors. Human errors consist of performance deficit, procedure or protocol not followed, miscommunication, inaccurate or omitted transcription, improper documentation, knowledge deficit, miscalculations, missing or misplaced zero and decimal points, use of non-standard abbreviations, lack of patient information and lack of patient understanding of their 
therapy ${ }^{[5]}$ Human errors are compounded when wards are overcrowded, leading to an increase in workload, generation of more stress, tiredness and sleep deprivation in the healthcare professional, which facilitates the occurrence of more medication errors. ${ }^{[4,5]}$ Factors that contribute to system errors include medications with similar names, complex or poorly designed electronic patient record technology, access to medication by non-pharmacy personnel, drug distribution system errors, computer entry error, lack of system safeguards, and workplace environmental problems that include the daily occupancy rate and the workload of the healthcare professionals. ${ }^{[5]}$

The severity of medication errors can be categorised (A - I) based on the effect they have on the patient, as constructed by the NCC MERP. ${ }^{[1,6,14]}$ Currently, in SA, there is no standardised medication error database for the identification and quantification of medication errors in hospitals. However, ongoing safety and effectiveness of medicines is ensured by voluntary reporting systems that form part of pharmacovigilance programmes. ${ }^{[15]}$ These programmes aim to detect, assess, manage and prevent drug-related problems. ${ }^{[15,16]}$

The importance of the presence of a clinical pharmacist in a paediatric unit to monitor drug treatment and prevent medication errors is well established in some countries. ${ }^{[7,9,17]}$ Clinical pharmacists monitoring medication orders might prevent more than half (58\%) of all errors, including $72 \%$ of potentially harmful errors. Furthermore, they may improve doctor-pharmacist communication, preventing $47 \%$ of all errors. ${ }^{[17]}$ The clinical pharmacist should be involved in double-checking all drug administrations to reduce medication errors. For preventive measures to be successful against medication errors there needs to be collaboration between all healthcare professionals. ${ }^{[13]}$

This study emphasises that it is the responsibility of the healthcare provider to ensure that patient safety incidents are instantly identified and managed to minimise patient harm and suffering, that errors are routinely investigated and managed to prevent repetition and to learn from errors. ${ }^{[18]}$ To this end the purpose of the study was to determine the incidence of medication errors in neonatal and paediatric inpatients, to investigate the origin of medication errors, and to describe and categorise the types of medication errors made in the neonatal intensive care unit (NICU) and paediatric wards in a tertiary academic hospital.

\section{Methods \\ Study design, study site and population}

This study followed an observational, quantitative, descriptive design that was done prospectively. It was conducted in four paediatric wards over a 16 -week period at a tertiary academic hospital, which has 28 clinical departments, and is one of four academic institutions in Gauteng Province. It provides a service to the surrounding populations of $\sim 1 \quad 700 \quad 000$ people. The hospital also receives referrals from Limpopo, North West and Mpumalanga provinces. In addition, this facility receives referrals from Southern African Development Community (SADC) countries, other tertiary academic hospitals, local specialists and general practitioners. The hospital has 1650 active beds, 22 approved ICU beds, 60 high-care beds and 17 theatres. The four paediatric wards under study consisted of a 40-bed orthopaedics ward, a 40-bed surgical ward, a 20-bed oncology ward and a 55-bed NICU.

\section{Data collection and data collection instruments}

Neonatal and paediatric inpatient medical files for background of the patient's disease and current condition and the patients' medication charts were reviewed to evaluate what was prescribed by the physicians and documented as administered by the nurses. The method of how and when nurses prepared (reconstituted) and administered medication to the patients was directly observed by the researcher. The dispensing process was evaluated for the correct drug, dosage form and on-time dispensing when a prescription was sent to the pharmacy. Direct observation occurred 5 - 7 hours per day, 5 days a week, for the 16-week study period.

A medication error checklist was designed according to recommendations from several studies. ${ }^{[5-10,14]}$ The definitions of the various types of errors were adopted from previous studies and are defined in Table $1 .^{[5,8,11,13,14]}$

The medication error checklist was validated in a pilot study of 10 patients and minor amendments were made. The checklist was subsequently used to capture the following information, as outlined by the objectives: the origin of medication errors (e.g. prescription or administration), the type of medication errors that occurred (e.g. incorrect dose or inadequate preparation) and the cause of the medication errors (e.g. miscalculation or inexperienced staff), after

\section{Table 1. Classification of types of medication errors}

\begin{tabular}{ll}
\hline Type of error & Definition of error \\
\hline Inadequate preparation of & $\begin{array}{l}\text { When medication was prepared } \\
\text { medication }\end{array}$ \\
& $\begin{array}{l}\text { includes incorrect method of } \\
\text { reconstitution or dilution, not } \\
\text { shaking the suspension thoroughly } \\
\text { and crushing of specially coated } \\
\text { tablets. }\end{array}$
\end{tabular}

Incorrect dose

Dose that was prescribed or administered was $>10 \%$ above or below the correct dose based on the patient's weight.

Incorrect duration Medication administered for a longer period of time than was prescribed, or prescribed medication that was not discontinued when indicated.

Incorrect frequency Medication administered at incorrect intervals (e.g. 8-hourly instead of 6-hourly).

Incorrect medication

Administration of medication that was not prescribed, misread prescription, or medication administered to the wrong patient.

Incorrect time There was $>1 \mathrm{~h}$ difference between the scheduled time and time of administration.

Mislabelling When reconstituted medication was kept in storage and had no label indicating the time of reconstitution and volume of diluent used. Infusion not labelled with the name or dose of medication that was being administered.

Omission

Failure to administer a prescribed medication, or medication that was being administered without noting that it had been dispensed.

Prescribing error (e.g. no route)

Elements of good prescribing practice were observed and each medication prescribed was evaluated for compliance with pharmacy legislation as stipulated in Good Pharmacy Practice, i.e. the correct name, dosage, units, route, frequency and duration of treatment. 
Table 2. Categorising medication errors

\begin{tabular}{|c|c|}
\hline Error and category & Harm and description \\
\hline No error & No harm \\
\hline Category A & $\begin{array}{l}\text { Circumstances or events that have the } \\
\text { capacity to cause harm }\end{array}$ \\
\hline Error & No harm \\
\hline Category B & $\begin{array}{l}\text { Error occurred but did not reach the } \\
\text { patient }\end{array}$ \\
\hline Category C & $\begin{array}{l}\text { Error occurred and reached the patient but } \\
\text { did not cause harm }\end{array}$ \\
\hline Category D & $\begin{array}{l}\text { Error occurred and reached the patient } \\
\text { - required monitoring to confirm that it } \\
\text { resulted in no harm to the patient and/or } \\
\text { required intervention to preclude harm }\end{array}$ \\
\hline Error & Harm \\
\hline Category E & $\begin{array}{l}\text { Error occurred - need for treatment or } \\
\text { intervention - temporary harm to patient }\end{array}$ \\
\hline Category F & $\begin{array}{l}\text { Error occurred - need for prolonged } \\
\text { hospitalisation - temporary harm to } \\
\text { patient }\end{array}$ \\
\hline Category G & $\begin{array}{l}\text { Error occurred that contributed to } \\
\text { permanent patient harm }\end{array}$ \\
\hline Category $\mathrm{H}$ & $\begin{array}{l}\text { Error occurred that required intervention } \\
\text { necessary to sustain life }\end{array}$ \\
\hline Error & Death \\
\hline Category I & Error occured that resulted in patient death \\
\hline
\end{tabular}

which it was categorised (Table 2) according to the NCC MERP for data analyses. ${ }^{[1]}$

\section{Data analysis}

The data from the medication error checklists were imported into Statistical Analysis System (SAS) release 9.3 (USA) for statistical analysis. Descriptive statistics were used to analyse and summarise data to obtain the frequency of occurrence of medication errors. Incidence of medication errors was calculated as a percentage with $95 \%$ confidence intervals (CIs). The $\chi^{2}$ test and $p$-value were calculated for homogeneity between the four wards, and the relative risk to an error was evaluated.

\section{Ethical considerations}

Ethical approval was obtained from the university associated with the hospital. The Medunsa Research Ethics Committee approved the study (MREC/H/225/2014: PG). Permission to perform this study at the tertiary academic hospital was obtained from the hospital's chief executive officer. All data were collected anonymously. Patient confidentiality was maintained by the allocation of a unique study number to each participant.

\section{Results \\ Demographics}

During the study period, 227 patient medication charts (47 neonates and 180 paediatric patients) were evaluated for medication errors. A total of 91 patients were female $(40 \%)$ and 136 patients were male $(60 \%)$. The ages of the patients were categorised according to paediatric terminology developed by the Eunice Kennedy Shriver National Institute of Child Health and Human Development (NICHD). ${ }^{[19]}$ Therefore, the study consisted of the following percentages: infants $(8 \%, n=15)$, toddlers $(17 \%, n=31)$, early childhood $(28 \%, n=50)$, middle childhood (39\%, $n=71)$, early adolescence $(7 \%, n=12)$, and one late adolescence. The median age of the patients was 5 years (interquartile range (IQR) 2 - 8 years, range 1 month - 19 years) and the neonates' mean age was 33 (standard deviation (SD) 3.89; range 25 - 40) weeks.

\section{Patient diagnoses and medicines prescribed}

The main causes of hospitalisation were respiratory distress syndrome, neonatal sepsis, babies born to HIV-positive mothers, B-cell acute lymphoblastic leukaemia, neonatal jaundice, adenotonsillectomy, tuberculosis and pneumonia. The most commonly prescribed medications were paracetamol, tilidine, amikacin, allopurinol, amoxicillin-clavulanic acid, benzylpenicillin, cloxacillin, ibuprofen, metronidazole, nevirapine and piperacillin-tazobactam.

\section{Incidence and nature of medication errors}

In total, 663 medication errors were detected among 227 patient files studied over 16 weeks, with one or more errors in 177 (78\%) patients and no errors in $50(22 \%)$ patients. The incidence of medication errors in the four paediatric wards was 2.9 per patient, per admission, over the 16-week observation period.

\section{Origin of medication errors}

A total of 715 medications were prescribed and studied over the 16-week study period. There were 309 (47\%) prescribing errors documented, with an overall prescribing error rate of $43 \%(95 \%$ confidence interval (CI) 39.6 - 46.9). The nurses were responsible for 338 administration errors (51\%), including labelling errors, giving an overall administration error rate of $47.3 \%$ (95\% CI 43.6 - 50.9). The pharmacy was responsible for 16 dispensing errors (2\%).

\section{Site of medication error}

Medication errors in the four paediatric wards were separately analysed (Table 3). The incidence of medication errors was tested using the $\chi^{2}$ test of homogeneity. It was used to determine whether frequency counts were distributed identically across the different paediatric wards. The results showed no homogeneity, meaning that the four wards differed in respect of the percentage of errors $(p<0.0001)$. The relative risk for medication errors was calculated using the number of medications observed and the incidence of errors per ward. The orthopaedic ward had the highest risk for medication errors compared with the other three wards.

\section{Types of medication errors}

The types of medication errors observed are shown in Fig. 1. Incorrect dose was the most frequent type of error that occurred, giving an overall incorrect dosing error rate of $34 \%$ (95\% CI 30.5 - 37.7) in 663 errors detected. This was followed by omission of medication $19 \%$ (95\% CI 15.5 - 21.4), medication given at the incorrect time $12 \%$ (95\% CI 9.2 - 14.1), incorrect frequency of administration 7.9\% (95\% CI 5.8 - 9.9) and inadequate preparation of medication $7.8 \%(95 \%$ CI 5.7 - 9.7). Other types of errors found were mislabelling (6.7\%), incorrect medication (4\%), no route of administration prescribed $(3.2 \%)$, incorrect duration of therapy $(1.7 \%)$ and no frequency prescribed (1\%). Examples of medication errors observed, and possible causes or reasons are shown in Table 4.

\section{Groups of medications with errors}

The most commonly prescribed medications for the four wards included anti-infectives and analgesics. The number of errors associated against the number of medication orders with these two classes are displayed in Fig. 2. Anti-infectives with the most errors, accountable for 284 (43\%) of the 663 errors, were: amoxicillinclavulanic acid, metronidazole, cloxacillin, cefuroxime, amikacin, benzylpenicillin, imipenem, piperacillin-tazobactam and gentamicin. 
Table 3. Frequency of errors in the four paediatric wards

\begin{tabular}{llllll}
\hline Ward & $\begin{array}{l}\text { Medications } \\
\text { observed, } \boldsymbol{n}\end{array}$ & Errors, $\boldsymbol{n}$ & $\chi^{2}$ & $\boldsymbol{p}$-value & $\begin{array}{l}\text { Relative } \\
\text { risk }\end{array}$ \\
\hline Orthopaedics & 87 & 113 & 44.68 & $<0.0001^{\star}$ & 1.299 \\
Surgery & 251 & 259 & & & 1.032 \\
Oncology & 241 & 185 & & & 0.768 \\
NICU & 136 & 106 & & & 0.779 \\
${ }^{*}$ Highly statistically significant. & & & &
\end{tabular}

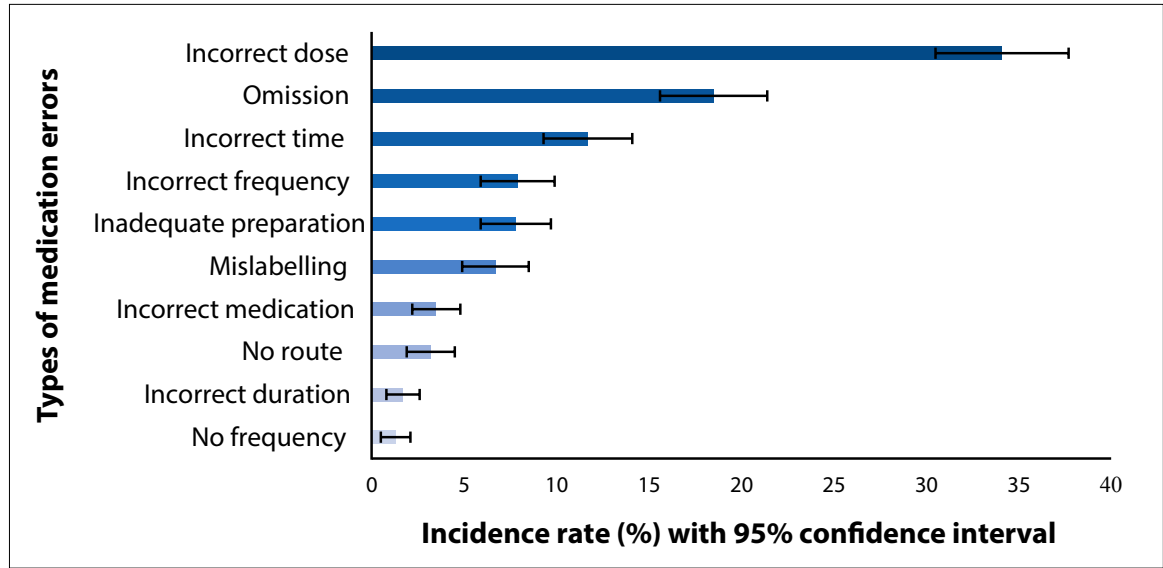

Fig. 1. Types of medication errors across the four paediatric wards.

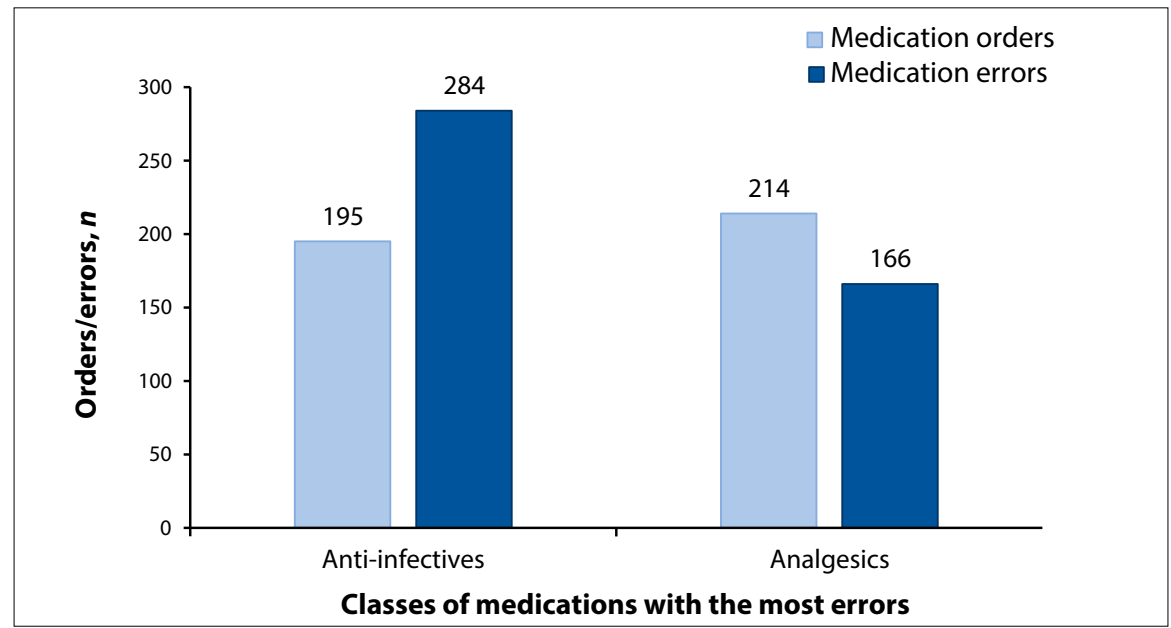

Fig. 2. Classes of medications with the number of times it was ordered and the number of medication errors observed.

Analgesics accountable for 166 (25\%) of the errors were: paracetamol, tilidine and ibuprofen. The remaining 213 (32\%) errors consisted of different medications from multiple classes. Paracetamol had the most medication errors, with 106 errors out of the total medication errors identified.

\section{Categorising medication errors}

Medication errors were classified into six categories $(\mathrm{A}-\mathrm{F})$ in the 177 patients with medication errors, according to severity (Table 2) ${ }^{[1]}$ Just more than $60 \%$ (118) of the patients who had medication errors did not suffer any harm (categories A - C), whereas of medication and correlates with similar studies that also identified these agents as commonly prescribed in paediatrics. ${ }^{[7,11,13,14]}$

The majority of studies conducted in paediatrics reporting medication errors declared medication error frequencies of between $11 \%$ and $54 \%{ }^{[2,4,7,8,14]}$ This is markedly lower than the frequency of medication errors (78\%) reported in this study.

Although the frequency of medication errors in this study is high, a number of factors may have led to biased findings, which actually resulted in an overall conservative estimate of errors reported. Firstly, although the doctors and nurses were unaware of the reasons for the observation, they were aware that they were being observed and might have changed their behaviour. Secondly, the research team tried to avoid as many interventions as they could to prevent observer-induced bias. However, in terms of the ethical principle of nonmaleficence, it would be unethical to allow medication administration errors to occur for the purpose of observation when it can cause direct, severe or irreversible harm. The researchers therefore had to intervene and prevent some errors from happening in cases where an observed error could cause harm to the patient. Examples of interventions by the researchers included the doctor being asked to change the high dose of $1 \mathrm{~g}$ paracetamol prescribed for a 2-yearold, to the recommended $180 \mathrm{mg}$, and the nurse being stopped before administering 12 drops of tilidine to a 1-year-old instead of two drops as prescribed. Lastly, the lack of observation of medication reconstitution and medication administration by nurses, 24 hours per day, 7 days per week, probably reduced the number of errors detected.

In the evaluation of the origin of medication errors, administration of medicines by nurses caused just over half $(51 \%)$ of all detected errors, with prescribing errors by doctors causing $47 \%$ of the medication errors. There is some variation in the literature with similar results reported by Khalili et al. ${ }^{[7]}$ and lower percentages in various other studies that ranged between $11.7 \%$ and $19 \%$ administration errors, and $11 \%$ and $34 \%$ prescribing errors. ${ }^{[2,8,13,14]}$ Dispensing errors amounted to $2 \%$ of the total errors, which may be due to the fact that most commonly prescribed medications are kept in the ward as ward stock.

The most prevalent type of error identified was incorrect dosing (34\%), followed by omission (19\%) and medication given at the incorrect time $(12 \%)$. Possible reasons for omission and incorrect time could include nursing staff being tasked with a number of non-nursing related duties, e.g. cleaning, admixture of medications and insertion of IV lines. This is consistent with similar studies that have also reported dosing errors. ${ }^{[3,4,6,7,14]}$ 
Table 4. Examples of medication errors observed, possible causes and reasons

\begin{tabular}{|c|c|c|c|c|}
\hline Type of error & $\begin{array}{l}\text { Frequency of error } \\
(n=663)\end{array}$ & Description of examples & $\begin{array}{l}\text { Possible causes or } \\
\text { reasons }(n)\end{array}$ & $\begin{array}{l}\text { Cause or reason, \% } \\
(95 \% \mathrm{CI})\end{array}$ \\
\hline \multirow[t]{4}{*}{ Incorrect dose } & \multirow[t]{4}{*}{226} & $\begin{array}{l}1 \mathrm{~g} \text { paracetamol prescribed instead } \\
\text { of } 180 \mathrm{mg} \text { (researcher intervened) }\end{array}$ & $\begin{array}{l}\text { Miscalculation (175), e.g. dose } \\
\text { prescribed was incorrectly calculated } \\
\text { based on patient's weight or protocol }\end{array}$ & \multirow[t]{4}{*}{$26.4(23.0-29.8)$} \\
\hline & & $\begin{array}{l}5 \mathrm{~mL} \text { paracetamol syrup given as } \\
500 \mathrm{mg} \text { tablet }\end{array}$ & \multirow{3}{*}{$\begin{array}{l}\text { Dose to be administered was } \\
\text { miscalculated due to limited } \\
\text { strength available }\end{array}$} & \\
\hline & & $\begin{array}{l}150 \mathrm{mg} \text { metronidazole prescribed } \\
\text { as } 60 \mathrm{mg}\end{array}$ & & \\
\hline & & $\begin{array}{l}2 \text { drops tilidine given as } 12 \text { drops for } \\
8 \text {-month-old (researcher intervened) }\end{array}$ & & \\
\hline \multirow[t]{3}{*}{ Omission } & \multirow[t]{3}{*}{122} & $\begin{array}{l}\text { Common medications not given: } \\
\text { paracetamol, tilidine and ibuprofen }\end{array}$ & $\begin{array}{l}\text { Failure to monitor (97), e.g. } \\
\text { prescription not checked to see what } \\
\text { must be administered }\end{array}$ & \multirow[t]{2}{*}{$14.7(11.9-17.3)$} \\
\hline & & $\begin{array}{l}\text { The nurse forgot to order antibiotics } \\
\text { from the phar-macy that is not part } \\
\text { of ward stock, patients missed doses }\end{array}$ & $\begin{array}{l}\text { Medication out of stock, no } \\
\text { communication with doctor to } \\
\text { prescribe an alternative }\end{array}$ & \\
\hline & & $\begin{array}{l}\text { Drip not inserted, patient failed to } \\
\text { receive intravenous (IV) medication }\end{array}$ & $\begin{array}{l}\text { No documentation (64) } \\
\text { Rule of thumb: if it was not signed it } \\
\text { was not administered }\end{array}$ & $9.7(7.4-11.9)$ \\
\hline \multirow[t]{3}{*}{ Incorrect time } & \multirow[t]{3}{*}{77} & $\begin{array}{l}\text { Prescription sent later to the } \\
\text { pharmacy, received antibiotics at the } \\
\text { incorrect time - administered at the } \\
\text { wrong time }\end{array}$ & $\begin{array}{l}\text { Increased workload ( } 68 \text { ), e.g. one } \\
\text { nurse for } 10 \text { patients or one nurse } \\
\text { for four babies }\end{array}$ & \multirow[t]{3}{*}{$10.3(8.0-12.6)$} \\
\hline & & $\begin{array}{l}\text { Medication given at } 14 \mathrm{~h} 00 \text { instead } \\
\text { of } 10 \mathrm{~h} 00\end{array}$ & $\begin{array}{l}\text { Responsible nurse too busy with } \\
\text { administration and other duties }\end{array}$ & \\
\hline & & $\begin{array}{l}\text { One nurse for four babies - } \\
\text { increased workload (drips to be } \\
\text { inserted, admixtures, nappy changes, } \\
\text { cleaning, updating files, etc.) }\end{array}$ & $\begin{array}{l}\text { Not enough nursing staff in the ward } \\
\text { (understaffed) }\end{array}$ & \\
\hline \multirow[t]{2}{*}{$\begin{array}{l}\text { Incorrect } \\
\text { frequency }\end{array}$} & \multirow[t]{2}{*}{52} & $\begin{array}{l}\text { Cloxacillin given 8-hourly instead of } \\
\text { 6-hourly, as prescribed }\end{array}$ & $\begin{array}{l}\text { Procedure not followed (96), e.g. } \\
\text { prescription not double-checked for } \\
\text { frequency prescribed }\end{array}$ & \multirow[t]{2}{*}{$14.5(11.8-17.2)$} \\
\hline & & $\begin{array}{l}\text { Imipenem prescribed as } 6 \text {-hourly for } \\
\text { all neonates instead of } 12 \text {-hourly or } \\
\text { 8-hourly when }<21 \text { days of age }\end{array}$ & $\begin{array}{l}\text { Antibiotic policy not followed } \\
\text { when prescribing antibiotics in the } \\
\text { neonate }\end{array}$ & \\
\hline \multirow{3}{*}{$\begin{array}{l}\text { Inadequate } \\
\text { preparation/ } \\
\text { incorrect } \\
\text { technique }\end{array}$} & \multirow[t]{3}{*}{51} & $\begin{array}{l}\text { Oral amoxicillin-clavulanic acid } \\
\text { mixed with tap water (sterile water } \\
\text { available) }\end{array}$ & $\begin{array}{l}\text { Inexperienced staff (67) e.g. nursing } \\
\text { students and new nursing staff }\end{array}$ & \multirow[t]{3}{*}{$10.2(7.8-12.4)$} \\
\hline & & $\begin{array}{l}\text { Used one needle to reconstitute all } \\
\text { IV medication for the ward }\end{array}$ & $\begin{array}{l}\text { Does not consult the package } \\
\text { insert or other reference sources } \\
\text { ofinformation }\end{array}$ & \\
\hline & & & $\begin{array}{l}\text { Tired after working multiple 12- } \\
\text { hour shifts }\end{array}$ & \\
\hline
\end{tabular}

Miller et al. ${ }^{[20]}$ had remarkably high incidences in both omission of medication (42\%) and the wrong time of administration (50\%), corresponding to Chua et al..$^{[13]}$ and Hicks et al. ${ }^{[6]}$

Inadequate knowledge, insufficient training and increased workload has been listed as major causes of medication errors. ${ }^{[4,69,13]}$ Similar findings were identified as the most prominent causes of medication errors in this study, miscalculation of dosages (26\%), failure to monitor therapy (15\%) and procedures (e.g. antibiotic policy) not followed (15\%).

The paediatric orthopaedic ward had the highest risk for medication errors, even though they had the lowest number of medications prescribed and administered. Reasons for this included the high number of analgesics prescribed for postoperative pain relief. Tilidine is frequently prescribed for pain relief in this ward. Medication errors observed included omission of doses and incorrect dosing of the agent. Tilidine is administered using an oral medicine dropper, with the possibility of drops being administered inconsistently (i.e. too fast or too slow). ${ }^{[21]}$ Small differences in the administration of this drug may result in either a lack of optimal pain relief (underdose) or harm (overdose). ${ }^{[21]}$

In the class of analgesics, paracetamol, tilidine and ibuprofen were identified as agents that caused the most errors. The literature pertaining to paracetamol is contradictory, with one study listing only five doses of paracetamol with errors ${ }^{[13]}$ and other studies listing many errors. ${ }^{[7,9,14]}$ Slightly less than half $(43 \%)$ of all medication errors were identified in the class of anti-infectives and is equal to studies that found numerous errors in antibiotics reported in paediatrics. $^{[3,9-11,13]}$ 
The greatest majority (87\%) of these medication errors that reached the patients did not cause harm according to the categories used by the NCC MERP. ${ }^{[1]}$ Alternative studies showed similar results, except where circumstances or events that had the capacity to cause harm were not included. ${ }^{[6,14]}$

\section{Study limitations and recommendations}

Only those errors observed by the researchers were used for analysis. Therefore several errors may have gone undetected. Other study limitations included validation of the tool used to determine error. Our tool was developed using reputable references.

Observation per se may also affect practice and result in a decrease of medication error rate. Observer bias could not be ruled out since observational research requires a lot of resources and referencing, and is time consuming.

Using a medication error checklist is fundamental to improve patient safety. It is therefore crucial for healthcare providers to identify weak points in the healthcare system regarding medication prescribing, administering and dispensing in paediatrics. Measures that may be implemented include a clinical pharmacist actively working with other healthcare providers in paediatric wards. This can improve the patient's healthcare outcomes and has been described in several studies. Reviewing patient medical charts and reporting medication therapy problems to the head of the medical team on a daily basis are part of the clinical pharmacist's daily responsibilities. ${ }^{[2,7,9,12,13,17]}$

Recommendations to reduce medication errors in the future include the implementation of training for paediatric nurses, doctors and pharmacists on aspects identified as part of the study, for e.g. steps to correct prescribing, how to reconstitute medication, and how to calculate dosages. Since medication preparations and administrations are the last line of defence against medication errors, an electronic medication error platform should be implemented to record and report medication errors.

\section{Conclusion}

This study showed that the frequency of medication errors in the paediatric ward of the teaching hospital was higher than that reported in similar studies elsewhere. Administration followed by prescription are the most error-prone steps in the paediatric medication process. Dosing errors are a common problem in paediatrics and, therefore, a formalised system to monitor errors should be introduced. Regular discussions on preventative measures among the multidisciplinary team should be initiated to further reduce the frequency of the errors. This study serves to create awareness and interest concerning medication safety in the paediatric population of SA.
1. National Coordinating Council for Medication Error Reporting and Prevention NCC MERP, 2014. http://www.nccmerp.org/ (accessed 28 January 2014).

2. Ghaleb MA, Barber N, Franklin BD, Wong ICK. The incidence and nature of prescribing and medication administration errors in paediatric inpatients. BMJ 2010;95(2):113-118. http://dx.doi.org/10.1136/adc.2009.158485

3. Jain S, Basu S, Parmar VR. Medication errors in neonates admitted in intensive care unit and emergency department. Indian J Med Sci 2009;63(4):145-151. http://dx.doi.org/10.4103/0019-5359.50763

4. Lerner RB, de Carvalho M, Vieira AA, Lopes JM, Moreira MA. Medication errors in a neonatal intensive care unit. Jornal de Pediatria 2008;84(4):166-170. http://dx.doi.org/10.1590/S0021-75572008000200013

5. Jhanjee A, Bhatia MS, Srivastava S. Medication errors in clinical practice. Delhi Psychiatry J 2011;14(2):205-210.

6. Hicks RW, Becker SC, Krenzicheck D, Beyea SC. Mediation errors in the PACU: A secondary analysis of MEDMARX findings. J PeriAnesth Nurs 2004;19(1):1828. http://dx.doi.org/10.1016/j.jopan.2003.11.007

7. Khalili H, Farsaei S, Rezaee H, Dashti-Khavidaki S. Role of clinical pharmacists' interventions in detection and prevention of medication errors in a medical ward. Int J of Clin Pharm Pharm Care 2011;33(2):281-284. http://dx.doi. org/10.1007/s11096-011-9494-1

8. Otero P, Leyton A, Mariani G, Cernadas JMC. Medication errors in pediatric inpatients: Prevalence and results of a prevention programme. J Am Acad Pediatr 2008;122(3):737-743. http://dx.doi.org/10.1542/peds.2008-0014

9. Wong ICK, Wong LYL, Cranswick NE. Minimising medication errors in children. Arch Dis Child 2008;94(2):161-164. http://dx.doi.org/10.1136/ adc. 2007.116442

10. Ross LM, Wallace J, Paton JY. Medication errors in a paediatric teaching hospital in the UK: Five years operational experience. BMJ 2000;83(6):492-497. http://dx.doi.org/10.1136/adc.83.6.492

11. Feleke Y, Girma B. Medication administration errors involving paediatric in patients in a hospital in Ethiopia. Trop J Pharm Res 2010;9(4):401-407. http:// dx.doi.org/10.4314/tjpr.v9i4.58942

12. Clifton-Koeppel R. What nurses can do right now to reduce medication errors in the neonatal intensive care unit. Newborn Infant Nurs Rev 2008;8(2):72-82 http://dx.doi.org/10.1053/j.nainr.2008.03.008

13. Chua SS, Chua HM, Omar A. Drug administration errors in paediatric wards: A direct observation approach. Eur J Pediatr 2009;169(5):603-611. http://dx.doi.org/10.1007/s00431-009-1084-z

14. Martines-Anton A, Sanchez IJ, Casanueva L. Impact of an intervention to reduce prescribing errors in a pediatric intensive care unit. Intensive Care Med 2012;38(9):1532-1538. http://dx.doi.org/10.1007/s00134-012-2609-x

15. Mehta U, Dheda, M, Steel G, et al. Strengthening pharmacovigilance in South Africa. S Afr Med J 2014;104(2):104-106. http://dx.doi.org/10.7196/SAMJ.7517

16. Maigetter K, Pollock AM, Kadam A, Ward K, Weiss, MG. Pharmacovigilance in India, Uganda and South Africa with reference to WHO's minimum requirements. Int J Health Pol Manag 2015;4(5):295-305. http://dx.doi. org/10.15171/ijhpm.2015.55

17. Simpson JH, Lynch R, Grant J, Alroomi L. Reducing medication errors in the neonatal intensive care unit. BMJ 2004;89(6):480-482. http://dx.doi org/10.1136/adc.2003.044438

18. National Department of Health $(\mathrm{NDoH})$. National Core Standards for Health Establishments in South Africa. Tshwane: NDoH, 2011. http://pmgassets.s3-website-eu-west-1.amazonaws.com/docs/120215abridge_0.pdf (accessed 10 October 2015).

19. Eunice Kennedy Shriver National Institute of Child Health and Human Development (NICHD). Pediatric Terminology: Current efforts. 2015. https:// www.nichd.nih.gov (accessed 20 November 2015)

20. Miller MR, Robinson KA, Lubomski LH, Rinke ML, Pronovost PJ. Medication errors in paediatric care: A systemic review of epidemiology and an evaluation of evidence supporting reduction strategy recommendations. Qual Saf Health Care J 2007;16(2):116-126. http://dx.doi.org/10.1136/qshc.2006.019950

21. Bauters T, Claus B, Willems E, et al. What's in a drop? Optimizing strategies for administration of drugs in paediatrics. Int J Clin Pharm 2012;34(5):679-681. http://dx.doi.org/10.1007/s11096-012-9670-y 